\title{
BPA in Baby Feeding PET Bottle, Aluminium Can and Thermal Printed Paper: Application of Acridine Orange Oxidation Inhibition Method to Estimate BPA
}

\section{Shruti S. Kapse}

The Maharaja Sayajirao University of Baroda Faculty of Science

Kumar Suranjit Prasad

Allahabad University: University of Allahabad

Bablu Prasad ( $\square$ akashganga812@gmail.com)

The Maharaja Sayajirao University of Baroda Faculty of Science https://orcid.org/0000-0001-75034270

\section{Research Article}

Keywords: Bisphenol-A (BPA), UV-Visible Spectrophotometer, Acridine Orange Oxidation, Analysis of BPA.

Posted Date: April 12th, 2021

DOl: https://doi.org/10.21203/rs.3.rs-355871/v1

License: (9) This work is licensed under a Creative Commons Attribution 4.0 International License. Read Full License 


\section{Abstract}

The leaching of Bisphenol-A (BPA) from plastic baby feeding bottles, aluminium cans and thermal printed receipts was investigated under aquatic condition at high temperature. Leached BPA was analysed using UV-Visible Spectrophotometer based on inhibitory effect of BPA on acridine orange oxidation, as a function of change in temperature and time of contact of water with the samples. Proposed method of BPA estimation method does not require any extraction and/or derivatization. The detection limit of BPA under current experimental setup was $0.1 \mathrm{ng} / \mathrm{ml}$. The results of BPA leached from baby feeding PET bottles, aluminium can with epoxy resin lining and thermal paper were $87 \pm 10 \mathrm{ng} / \mathrm{bottles}, 68 \pm 5 \mathrm{ng} / \mathrm{bottle}$ and $110 \pm 15 \mathrm{ng} /$ receipt under the current experimental conditions.

\section{Introduction}

Bisphenol-A (BPA) is a high-volume industrial chemical obtained by the condensation of acetone and phenol. It has drawn global attention in recent years due its ability to interfere with the functioning of endocrine systems. It is widely used in the manufacturing of food storage containers including feeding and non-returnable bottles, as BPA based polymer is clear and tough. BPA is also used as colour developer in carbonless copy paper and thermal receipt papers(Zhuang et al. 2014; Yousif Hammad 2015; Adeyi and Babalola 2019). Transport and processing of BPA and BPA containing products are foremost sources of pre-consumer release. However, post-consumer sources include those associated with disposal or waste including effluent discharge from municipal wastewater treatment plants, leaching from landfills, combustion of domestic waste, and degradation of plastics in the environment(Aschberger et al. 2010a; Corrales et al. 2015). It is acutely toxic to many organisms and belong to category 1 of Endocrine Disruptive Chemicals(Adeyi and Babalola 2019). In addition, it has been associated with carcinogenesis and increased sensitivity of certain cell types like mammary, epithelial and thyroid(Nomiri et al. 2019). Dermal and oral exposure is considered to be a main source of human exposure of BPA(Russo et al. 2017). Recently, it has been estimated that around 1-5 $\mu \mathrm{g} \mathrm{BPA} / \mathrm{kg}$ body weight is taken by humans on a daily basis due to extensive use and disposal of BPA containing product(Murata and Kang 2018).

Polymeric additives and flexibilities agent such as phthalate esters has been well documented for their cumulative human exposure and their effect(Prasad 2021). However, cumulative human exposure of BPA and its effect should be crucial to understand overall risk associated with BPA containing product uses and disposal. Due to ubiquitous in nature, it has become important to monitor the exposure of the chemical to humans in addition to environmental compartments. In addition, quantification of trace amount of BPA leached from food contact materials and other human exposure sources could be crucial to manage these widespread pollutants. Number of analytical methods has been developed to monitor BPA in environmental compartments with their limitations including HPLC, GC-MS, FTIR, and Spectrophotometry (Russo et al. 2017). However, a UV-Visible Spectrophotometric method based on inhibitory effect of BPA on acridine orange oxidation with hydroxyl radical was reported to be simple, accurate and rapid(Zhang et al. 2014). The major goal of this study is to monitor and analyse the amount 
of BPA released from the baby feeding plastic bottle, aluminium can and thermal printed paper in aquatic phase as a function of time and temperature.

\section{Materials And Methods}

\subsection{Chemicals and Materials}

BPA were purchased from Merck Limited, India. All other chemicals used were of high purity and analytical grade. All experiments were performed in triplicate unless otherwise specified. Baby feeding PET bottle and Aluminium can with carbonated cold drink of $200 \mathrm{ml}$ capacity were purchased from local market of Vadodara, Gujarat, India. Thermal printed paper of $12 \mathrm{~cm} \times 6 \mathrm{~cm}$ was procured from local ATM machine. All the glass wares were cleaned with $50 \%$ nitric acid and dried in oven at $120^{\circ} \mathrm{C}$ before the experiments.

\subsection{Preparation of samples}

The thermal printed papers $(12 \mathrm{~cm} \mathrm{X} 6 \mathrm{~cm}$ ) were emerged in a $200 \mathrm{ml}$ deionized water and vigorously mixed at $60^{\circ} \mathrm{C}$. However, in case of Aluminium cans and baby feeding PET bottles, $200 \mathrm{ml}$ deionized water was added inside to analyse BPA leached in aquatic conditions at $60^{\circ} \mathrm{C}$. Five $\mathrm{ml}$ samples were aliquoted at specific time interval up to 96 hours and filtered through $0.45 \mu \mathrm{m}$ filter paper to remove suspended particles before analyse. Nitric acid treated borosil glass were used as control.

\subsection{Analysis of BPA}

The stock solution of $1 \mathrm{mg} / \mathrm{ml}$ of BPA was prepared by dissolving BPA in HPLC grade deionized water. In order to homogenise, stock solution was maintained at $40^{\circ} \mathrm{C}$ for 24 hours with constant stirring on magnetic stirrer-cum hot plate. The stock solution was kept away from light and stored in a refrigerator. Acridine orange oxidation reaction was setup as per the optimized protocol developed by Zhange et al, 2014 with modification in a $25 \mathrm{~mL}$ volumetric flask under the batch mode containing $0.3 \mathrm{mg}$ Acridine Orange, 1.25 mmole sulfuric acid, 2.5 mmole Ferrous sulfate and 0.5 mmole $\mathrm{H}_{2} \mathrm{O}_{2}$ in deionised water. In order to find inhibitory effect of BPA on acridine orange oxidation a varying concentrations of BPA standard solution $(1.0 \mu \mathrm{g} / \mathrm{mL})$ were added in the reaction mixture. A blank experiment was setup with all reaction mixture except BPA solution to estimate total oxidation without inhibition. To estimate concentrations of BPA in test samples, all the reaction mixtures were added along with $5 \mathrm{~mL}$ of samples in place of standard BPA. The standard, blank and test solutions were heated in the water bath at $50.0 \pm$ $0.2^{\circ} \mathrm{C}$ for 10 mins and then allowed to cool down at room temperature before analysis using Agilent Cary 60 UV-visible Spectrophotometer. The absorption spectra of standard BPA, blank and test solutions along with the reaction mixture were measured in the range of 200 to $1100 \mathrm{~nm}$ to analyse inhibitory effect of BPA and test samples. The rate of oxidation of the catalytic reaction and non-catalytic reaction were calculated at absorbance at $265 \mathrm{~nm}$ to estimate amount of BPA present in the analysed sample.

\section{Results And Discussion}


The inhibitory effect of BPA on acridine orange oxidation by hydroxyl radical from Fenton reaction in acid medium was observed to be significant to establish co-relation between trace amount of BPA with oxidation inhibition (Fig. 1). Calibration curves were derived from absorbance data at $265 \mathrm{~nm}$ for BPA estimation in the range of $1 \mathrm{ng}$ to $100 \mathrm{ng}$ with a linear correlation coefficient of 0.948 . Interferences in analysis due to other inorganic and organic constituents present in the samples were considered insignificant since more than 1000 time of $\mathrm{Na}^{+}, \mathrm{K}^{+}$and $\mathrm{Mn}^{2+}$ than BPA did not show any significant interferences during analysis of BPA using similar method(Zhang et al. 2014). However, presence of phenol, p-nitrophenol, aniline and salicylic acid up to 5 times than BPA content showed marginal effect on the accuracy of BPA determination(Zhang et al. 2014).

Baby feeding PET bottles and aluminium can with epoxy resin lining used in this experiment leached 87 $\pm 10 \mathrm{ng} /$ bottles and $68 \pm 5 \mathrm{ng} /$ bottle of BPA, respectively in the course of 4 days at room temperature followed by heating of 1 hour on day 1 at $60^{\circ} \mathrm{C}$. However, tolerable daily intake (TDI) and specific migration limit of BPA has been reported as $4 \mu \mathrm{g} / \mathrm{kg}$ of body weight/day and $0.05 \mathrm{mg} / \mathrm{kg}$, respectively(European Food Safety Authority (EFSA), Parma 2015). On other hand, the worst-case scenario has been reported to be 1.6 and $0.8 \mu \mathrm{g} / \mathrm{kg}$ of body weight for newly born and infant baby, respectively by EU risk assessment(Aschberger et al. 2010b). Leaching of BPA from polymers and aluminium can has been often linked with manufacturer standards and environmental conditions including temperature, duration of storage, sunlight, humidity and contact with other materials(Le et al. 2008). For an example, Cooper et al (2011) has reported in the range of 0.08 to $1.9 \mathrm{mg} / \mathrm{l}$ due to different manufacturers standards followed during manufacturing of cans and exposure duration and time(Cooper et al. 2011). In current investigation, results were consistent with the literature and the trend of BPA release in baby bottles were increased by more than $54 \%$ from 24 hours to 48 hours. However, maximum amount of BPA was leached within 96 hours of incubation. Further incubation of baby bottles with water did not show any significant change in amount of BPA leached. The amount of BPA leached under current experimental conditions were within the safe limit, considering specific migration limit and worst case scenario for infants and new-born. Although, in this study there was no BPA reported in the detectable range during heating, it could be because the temperature decided was 60 considering real life conditions as cans do not contain anything boiling hot inside of them. There was an increase of $72.7 \%$ in BPA leaching from day 2 to day 4 which implies that in this particular study, time of contact played more important role in BPA migration in aluminium cans as compared to rise in temperature, if that is the case beverage cans which can be stored in the refrigerator may leach BPA over time even though the temperature is low. Moreover, the method used in this study was only tested on plastic products before, so the interferences other than the ones reported in this paper can play a role in unusual BPA determination. A study conducted by University of Texas School of Public health in 2010 found BPA in 63 out of 105 samples of fresh and canned foods, including canned infant formula(Yousif Hammad 2015). Intentional heating for sterilization or unintentional heating during storage and transportation of plastic bottles or aluminium cans can release BPA and its derivatives to food and drinks in variable quantities(Nugroho et al. 2019). 
The results of BPA leached from thermal paper were $110 \pm 15 \mathrm{ng} /$ receipt considering all the experimental conditions. Although, this method should not be considered very accurate for BPA determination from thermal paper because soaking of paper in water involved degradation of paper and that could have released more materials which would have interacted with actual concentration of BPA. A comparative study needs to be carried out of BPA determination using the method reported in this study and compare the results with HPLC or other methods. BPA in thermal papers are loosely bounded in monomeric forms that can be readily transferred to any surface that comes in contact even by touching them with our hands. In addition, BPA in thermal papers does not require any harsh acidic or heat conditions to facilitate migration from the source(Babu et al. 2015). Even though nobody usually soaks thermal papers in water, but due to improper recycling process or bad disposal practices, thermal papers end up in landfill sites and also enter in water bodies. Even trace amount of BPA has an environmental concern since it has been reported to be an effective EDC and also have synergistic toxic effects with other chemicals(Russo et al. 2017).

\section{Conclusion}

Method used under current investigation showed a very accurate and significant for the analysis of BPA up to nano gram level in environmental samples without any extraction and purification techniques. The results obtained for all the samples were found to be below TDI and SML. However, cumulative human exposure should be crucial to understand overall risk since BPA has been reported in all environmental compartments.

\section{Declarations}

Authors' contributions: Shruti S. Kapse contributed in literature data acquisition, analysis and writing of the original manuscript, Kumar Suranjit Prasad and Bablu Prasad contributed equally in conceptualization, writing and editing of the review form.

Availability of data and materials: All the data analysed during the current study are available from the corresponding author on reasonable request. BPA used during current investigation are available with Merck Limited, India and Baby feeding PET bottle and Aluminium can with carbonated cold drink of 200 $\mathrm{ml}$ capacity were purchased from local market of Vadodara, Gujarat, India. Thermal printed paper of 12 $\mathrm{cm} \times 6 \mathrm{~cm}$ was procured from local ATM machine.

Funding: Not applicable

Compliance with ethical standards:

Conflict of interest: Authors declare no any conflict of interest.

Ethics approval and consent to participate: Not applicable. 
Consent for publication: Not applicable

\section{Acknowledgment}

The authors would like to thank The Maharaja Sayajirao University of Baroda for providing the necessary infrastructure to carry out this research.

\section{References}

Adeyi AA, Babalola BA (2019) Bisphenol-A (BPA) in Foods commonly consumed in Southwest Nigeria and its Human Health Risk. Sci Rep 9:17458. https://doi.org/10.1038/s41598-019-53790-2

Aschberger K, Castello P, Hoekstra E, et al (2010a) Bisphenol A and baby bottles: challenges and perspectives. Luxembourg: Publications Office of the European Union

Aschberger K, Castello P, Hoekstra E, et al (2010b) Bisphenol A and Baby Bottles: Challenges and Perspectives. Eur Comm Jt Res Cent Inst Heal Consum Prot

Babu S, Uppu SN, Martin B, et al (2015) Unusually high levels of bisphenol A (BPA) in thermal paper cash register receipts (CRs): development and application of a robust LC-UV method to quantify BPA in CRs. Toxicol Mech Methods 25:410-416. https://doi.org/10.3109/15376516.2015.1045661

Cooper JE, Kendig EL, Belcher SM (2011) Assessment of bisphenol A released from reusable plastic, aluminium and stainless steel water bottles. Chemosphere 85:943-947.

https://doi.org/https://doi.org/10.1016/j.chemosphere.2011.06.060

Corrales J, Kristofco LA, Steele WB, et al (2015) Global Assessment of Bisphenol A in the Environment: Review and Analysis of Its Occurrence and Bioaccumulation. Dose Response 13:15593258155983081559325815598308. https://doi.org/10.1177/1559325815598308

European Food Safety Authority (EFSA), Parma I (2015) Scientific Opinion on the risks to public health related to the presence of bisphenol A (BPA) in foodstuffs. EFSA J 13:.

https://doi.org/10.2903/j.efsa.2015.3978

Le HH, Carlson EM, Chua JP, Belcher SM (2008) Bisphenol A is released from polycarbonate drinking bottles and mimics the neurotoxic actions of estrogen in developing cerebellar neurons. Toxicol Lett 176:149-156. https://doi.org/10.1016/j.toxlet.2007.11.001

Murata M, Kang J-H (2018) Bisphenol A (BPA) and cell signaling pathways. Biotechnol Adv 36:311-327. https://doi.org/https://doi.org/10.1016/j.biotechadv.2017.12.002

Nomiri S, Hoshyar R, Ambrosino C, et al (2019) A mini review of bisphenol A (BPA) effects on cancerrelated cellular signaling pathways. Environ Sci Pollut Res 26:8459-8467.

https://doi.org/10.1007/s11356-019-04228-9 
Nugroho B, Pramudya Y, Widodo W (2019) The Content Analysis of Bisphenol A (BPA) on Water in Plastic Glass with Varying Temperatures and Contact Times using UV-VIS Spectrophotometer. Indones Rev Phys 1:27. https://doi.org/10.12928/irip.v1i2.263

Prasad B (2021) Phthalate pollution: environmental fate and cumulative human exposure index using the multivariate analysis approach. Environ Sci Process Impacts. https://doi.org/10.1039/D0EM00396D

Russo G, Barbato F, Grumetto L (2017) Monitoring of bisphenol A and bisphenol S in thermal paper receipts from the Italian market and estimated transdermal human intake: A pilot study. Sci Total Environ 599-600:68-75. https://doi.org/10.1016/j.scitotenv.2017.04.192

Yousif Hammad A (2015) Determination Amount of Bisphenol A in Drugs and Water Drinking Container in Khartoum State, Sudan. Int J Nutr Food Sci 4:609. https://doi.org/10.11648/j.ijnfs.20150406.12

Zhang P, Gao C, Zhao B, Sun G (2014) Using data mining and UV-VIS spectrophotometric to determine the content of bisphenol A in plastics. J Chem Pharm Res 6:2553-2557

Zhuang Y, Zhou M, Gu J, Li X (2014) Spectrophotometric and high performance liquid chromatographic methods for sensitive determination of bisphenol A. Spectrochim Acta A Mol Biomol Spectrosc 122:153157. https://doi.org/10.1016/j.saa.2013.11.015

\section{Figures}

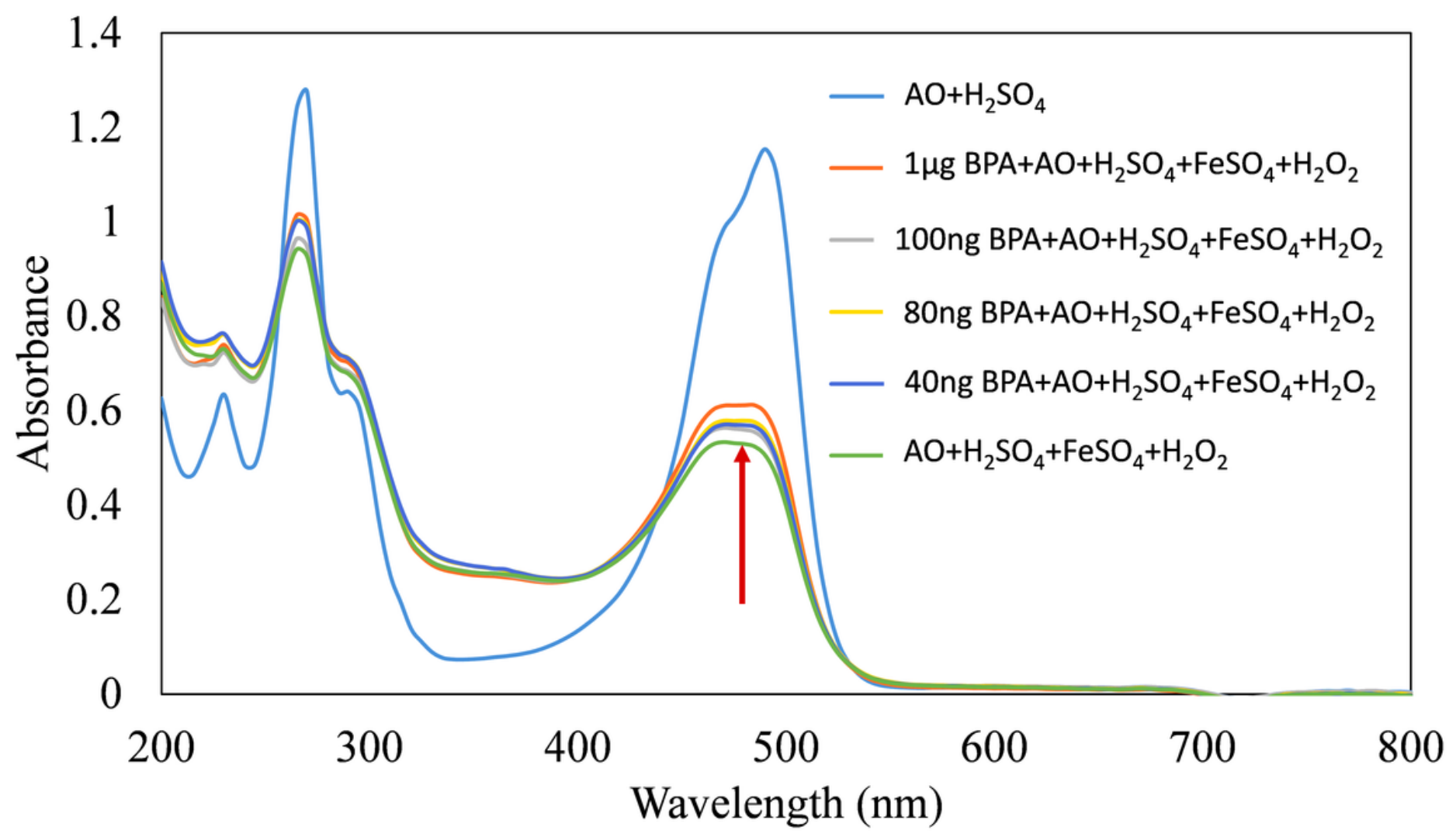




\section{Figure 1}

UV-visible spectrum of acridine orange oxidation by Fenton reagent and their inhibition using BPA

\section{Supplementary Files}

This is a list of supplementary files associated with this preprint. Click to download.

- GraphicalAbstract.docx

- EnvironmentalSignificance.docx 